University of Wollongong

Research Online

Faculty of Engineering and Information

Faculty of Engineering and Information

Sciences - Papers: Part A

Sciences

$1-1-2015$

Fractional order modelling of the cumulative deformation of granular soils under cyclic loading

Yifei Sun

University of Wollongong, ys910@uowmail.edu.au

Yang Xiao

Chongqing University, hhuxyanson@163.com

Khairul Fikry Hanif

University of Western Australia

Follow this and additional works at: https://ro.uow.edu.au/eispapers

Part of the Engineering Commons, and the Science and Technology Studies Commons

Research Online is the open access institutional repository for the University of Wollongong. For further information contact the UOW Library: research-pubs@uow.edu.au 


\title{
Fractional order modelling of the cumulative deformation of granular soils under cyclic loading
}

\begin{abstract}
To model the cumulative deformation of granular soils under cyclic loading, a mathematical model was proposed. The power law connection between the shear strain and loading cycle was represented by using fractional derivative approach. The volumetric strain was characterized by a modified cyclic flow rule which considered the effect of particle breakage. All model parameters were obtained by the cyclic and static triaxial tests. Predictions of the test results were provided to validate the proposed model. Comparison with an existing cumulative model was also made to show the advantage of the proposed model.

Disciplines

Engineering | Science and Technology Studies

\section{Publication Details}

Sun, Y., Xiao, Y. \& Hanif, K. Fikry. (2015). Fractional order modelling of the cumulative deformation of granular soils under cyclic loading. Acta Mechanica Solida Sinica, 28 (6), 647-658.
\end{abstract}




\title{
FRACTIONAL ORDER MODELLING OF THE CUMULATIVE DEFORMATION OF GRANULAR SOILS UNDER CYCLIC LOADING
}

\author{
Yifei Sun ${ }^{1}$, Yang Xiao ${ }^{2}$, Khairul Fikry Hanif ${ }^{3}$ \\ 1. Institute for Mathematics and its Applications, University of Wollongong, Wollongong 2522, Australia \\ 2. College of Civil Engineering, Chongqing University, Chongqing 400045, China \\ 2. Faculty of Engineering, Computing and Mathematics, University of Western Australia, Perth 6907, Australia
}

ABSTRACT: To model the cumulative deformation of granular soils under cyclic loading, a mathematical model is proposed. The power law connection between the shear strain and loading cycle is represented by using fractional derivative approach. The volumetric strain is characterized by a modified cyclic flow rule which considers the effect of particle breakage. All model parameters can be obtained by the cyclic and static triaxial tests. Predictions of the test results are provided to validate the proposed model. Comparison with an existing cumulative model is also performed to show the advantage of the proposed model.

KEY WORDS: cumulative deformation; cyclic stress; cyclic flow rule; fractional derivative; granular soil

\section{INTRODUCTION}

Well-constructed infrastructure could still suffer differential foundation settlements and structural damages if they were exposed to continuous cyclic loadings induced by traffics, construction activities and even sea waves, etc. If the number of loading cycles is sufficiently large then even relatively small strain amplitudes may endanger the serviceability of structures in the long run, especially if their displacement tolerance is small. Miura et al. [1] reported that the additional monitoring settlement of Saga airport road resulted from landing and taking off of aircraft reached about $150 \mathrm{~mm}$ in just 2 years. In addition, the tunnel settlement of the Shanghai Metro Line 1 caused by dynamic train loading had reached up to $155 \mathrm{~mm}$ in only 4 years [2]. Detailed understanding of the cumulative deformation and failure mechanism of soils under repeated loading with large number of cycles is thus essential for the proper design and maintenance of airport roads, railway tracks and highway pavements, etc. To investigate and constitutive modeling of the cyclic stress strain response of soils, lots of experimental and theoretical studies have been conducted [3-15]. Khalili et al. [7] and Liu et al. [12] studied the cyclic behaviour of gravelly soil under cyclic loading with low frequency. Ishikawa et al. [16] examined the mechanical response of railroad ballast subjected to repeated train passages on ballasted track by using multi-ring shear test. Suiker et al. [17] and Indraratna et al. [18-20] investigated the cyclic behaviour of both ballast and subballast under low and high loading frequency, from which the influences of loading history and confining pressure as well as the loading frequency were observed. These excellent works provide fundamental tools for further understanding the cyclic behaviour of granular soils, which is significant in practical design methods for the stability of both over- 
ground and underground structures. However, some of the tests only covered a cyclic load with very small loading cycles, say less than 100 . The corresponding constitutive models, such as the bounding surface model [7, 21] and the generalized plasticity model [22-23] can only simulate the cyclic behaviour of granular soils for very limited cycles. For the cumulative strain under high loading cycles $\left(\mathrm{N}>10^{3}\right)$, these models usually failed due to the unintentional accumulation of numerical errors and the huge calculation effort, especially in the finite element analysis. It is of little possibility for these theoretical models to be used in practical engineering where the loads usually have at least tens of thousands of cycles. To overcome this limitation, lots of empirical and semi-empirical models were proposed. For example, Indraratna et al. [24] proposed a pressure-dependent elastoplastic model by introducing empirical parameters to consider the effect of stress history, stress ratio, number of cycles, and breakage. In fact, the cumulative deformation of granular soils under cyclic stress is not only influenced by the current loading stress but also affected by previous loading cycles. It is indeed a memory-intensive phenomenon which can be mathematically expressed by a simple power law of the loading cycles, $N$, as suggested by Chrismer and Selig [25] and Indraratna et al. [26], etc. Inspired by the creep of soils under constant static stress, lots of empirical models for predicting cumulative deformation of granular soils, such as sand, ballast and subballast, etc., subjected to averaged cyclic deviator stress were suggested [5-6, 8-11]. Due to the explicit expressions, these models can be easily incorporated in the engineering-oriented finite element method. However, most of the existing models contain a lot of model parameters and even so still cannot well predict the accumulation of residual strain in soils subjected to cyclic loading with many cycles. Most importantly, they did not physically explain the reason for the cumulative deformation of granular soils evolving in a power law. Sun et al. [27-28] suggested the use of fractional calculus in modeling the dependency of power law in complex mechanical process. Later, Yin et al. [29-30] proposed a framework for constitutive modeling the strain hardening and softening of geomaterials under static loading by employing the basic theory of fractional derivative. However, fractional order constitutive modeling of cumulative behaviour of soils under cyclic loading is still rarely reached. The aim of this paper is to make an attempt to model the cumulative shear strain of granular soils subjected to drained cyclic loading based on the theory of fractional derivative. Moreover, a modified cyclic flow rule considering the effect of particle breakage is proposed for determining the corresponding cumulative volumetric strain. Comparison between the experimental results and model predictions is also presented.

\section{CUMULATIVE STRAIN BASED ON FRACTIONAL CALCULUS}

\subsection{General formula}

To quantify the cyclic behaviour of granular soils, laboratory tests, including the biaxial and triaxial tests are usually conducted under either constant stress rate $(d \sigma)$ or constant strain rate $(d \varepsilon)$. By regarding the soil as an intermediate material, lying between the ideal solids 
which obey Hooke' law and the Newtonian fluids which satisfy Newton's law of viscosity, the stress $(\sigma)$ and strain $(\varepsilon)$ relationship should obey [29]

$$
\sigma(t)=G \frac{d^{\alpha} \varepsilon(t)}{d t^{\alpha}}
$$

where $\alpha$ denotes the fractional derivative order, ranging between 0 and 1 . With $\alpha$ approaching 1, the material behaves increasingly like an ideal solid, whereas it becomes increasingly softer like a fluid with $\alpha$ approaching $0 . G$ is a material constant. $t$ denotes the time for loading and unloading. To start with, the Riemann-Liouville definitions of the fractional order derivative (Eq. (2)) and integral (Eq. (3)) of function $f$ are used [30]:

$$
\begin{gathered}
\frac{d^{\alpha} f}{d t^{\alpha}}=\frac{1}{\Gamma(1-\alpha)} \frac{d}{d t} \int_{0}^{t} \frac{f(\tau)}{(t-\tau)^{\alpha}} d \tau \\
\frac{d^{-\alpha} f}{d t^{-\alpha}}=\frac{1}{\Gamma(\alpha)} \int_{0}^{t} \frac{f(\tau)}{(t-\tau)^{1-\alpha}} d \tau
\end{gathered}
$$

where $\Gamma(\bullet)$ denotes the gamma function and can be formulated as

$$
\Gamma(t)=\int_{0}^{\infty} e^{-\tau} \tau^{t-1} d \tau
$$

For soils loaded and then unloaded for $N$ cycles, the total strain can be obtained by summing the strain of each loading and unloading cycle, that is

$$
\begin{aligned}
\varepsilon(t) & =\frac{1}{G_{1}} \frac{1}{\Gamma(\alpha)} \int_{0}^{\frac{T}{2}} \frac{\sigma(\tau)}{(t-\tau)^{1-\alpha}} d \tau+\frac{1}{G_{1}^{\prime}} \frac{1}{\Gamma(\alpha)} \int_{\frac{T}{2}}^{T} \frac{\hat{\sigma}(\tau)}{(t-\tau)^{1-\alpha}} d \tau \\
& +\frac{1}{G_{2}} \frac{1}{\Gamma(\alpha)} \int_{T}^{T+\frac{T}{2}} \frac{\sigma(\tau)}{(t-\tau)^{1-\alpha}} d \tau+\frac{1}{G_{2}^{\prime}} \frac{1}{\Gamma(\alpha)} \int_{T+\frac{T}{2}}^{2 T} \frac{\hat{\sigma}(\tau)}{(t-\tau)^{1-\alpha}} d \tau \\
& +\cdots+\frac{1}{G_{N}} \frac{1}{\Gamma(\alpha)} \int_{(N-1) T}^{(N-1) T+\frac{T}{2}} \frac{\sigma(\tau)}{(t-\tau)^{1-\alpha}} d \tau+\frac{1}{G_{N}^{\prime}} \frac{1}{\Gamma(\alpha)} \int_{(N-1) T+\frac{T}{2}}^{N T} \frac{\hat{\sigma}(\tau)}{(t-\tau)^{1-\alpha}} d \tau
\end{aligned}
$$

where the time, $T$, denote the loading period for one complete loading and unloading process. $\sigma$ and $\hat{\sigma}$ denote the loading and unloading stresses, respectively. $G_{i}$ and $G_{i}^{\prime}(i=1,2,3, \ldots$, $N$ ) are the loading and unloading moduli, respectively. Rearranging Eq. (5), one has

$$
\varepsilon(t)=\sum_{i=1}^{N} \frac{1}{G_{i}} \frac{1}{\Gamma(\alpha)} \int_{(i-1) T}^{(i-1) T+\frac{T}{2}} \frac{\sigma(\tau)}{(t-\tau)^{1-\alpha}} d \tau+\sum_{i=1}^{N} \frac{1}{G_{i}^{\prime}} \frac{1}{\Gamma(\alpha)} \int_{(i-1) T+\frac{T}{2}}^{i T} \frac{\hat{\sigma}(\tau)}{(t-\tau)^{1-\alpha}} d \tau
$$

Following Yin et al. [29], for soils tested under triaxial loading condition, the shear strain $\varepsilon_{s}$ and volumetric strain can be reformulated by using Eq. (6) as

$$
\varepsilon_{s}=\sum_{i=1}^{N} \frac{1}{G_{i}} \frac{1}{\Gamma(\alpha)} \int_{(i-1) T}^{(i-1) T+\frac{T}{2}} \frac{q(\tau)}{(t-\tau)^{1-\alpha}} d \tau+\sum_{i=1}^{N} \frac{1}{G_{i}^{\prime}} \frac{1}{\Gamma(\alpha)} \int_{(i-1) T+\frac{T}{2}}^{i T} \frac{\hat{q}(\tau)}{(t-\tau)^{1-\alpha}} d \tau
$$




$$
\varepsilon_{v}=\sum_{i=1}^{N} \frac{1}{K_{i}} \frac{1}{\Gamma(\alpha)} \int_{(i-1) T}^{(i-1) T+\frac{T}{2}} \frac{p^{\prime}(\tau)}{(t-\tau)^{1-\alpha}} d \tau+\sum_{i=1}^{N} \frac{1}{K_{i}^{\prime}} \frac{1}{\Gamma(\alpha)} \int_{(i-1) T+\frac{T}{2}}^{i T} \frac{\hat{p}^{\prime}(\tau)}{(t-\tau)^{1-\alpha}} d \tau
$$

where $\varepsilon_{s}=2 / 3\left(\varepsilon_{1}-\varepsilon_{3}\right)$ and $\varepsilon_{v}=\left(\varepsilon_{1}+2 \varepsilon_{3}\right) ; \varepsilon_{1}$ and $\varepsilon_{3}$ are the first and third principal strains, respectively. $q\left(=\sigma_{1}^{\prime}-\sigma_{3}^{\prime}\right)$ and $p^{\prime}\left(=\sigma_{1}^{\prime}+2 \sigma_{3}^{\prime}\right) / 3$ are the loading deviator and mean effective principal stresses, respectively; $\sigma_{1}^{\prime}$ and $\sigma_{3}^{\prime}$ are the first and third effective principal stresses, respectively. $\hat{q}$ denote the unloading deviator stresses. $K_{i}$ and $K_{i}^{\prime}(i=1,2,3, \ldots, N)$ are the volumetric loading and unloading moduli, respectively. Note that $d q=d \sigma_{1}^{\prime}$ and $d p^{\prime}=d \sigma_{1}^{\prime} / 3$ during loading and $d \hat{q}=-d \sigma_{1}^{\prime}$ and $d \hat{p}^{\prime}=-d \sigma_{1}^{\prime} / 3$ during unloading.

\subsection{Formula for long-term deformation}

It is noted that Eq. (6) strictly counts the strain variation of each individual loading cycle. The entire iteration steps may cause huge calculation effort and numerical errors if large amounts of loading cycles are involved. Therefore, a modified fractional order model for long-term cyclic loading needs to be proposed. As adopted by Indraratna et al. [24, 26] as well as Chrismer and Selig [25], the power law connection between the cumulative strain and its corresponding loading cycles can well predict the long-term deformation of granular soils. Most importantly, it can be easily implemented in the finite element analysis because of its explicit expression. To better take into account this power law phenomenon, the fractional derivative is employed here. For cyclic triaxial test as schematically illustrated by Fig. 1, the cumulative shear strain $\varepsilon_{s}^{p}$ is assumed to result from the average deviator stress $q^{\text {av }}$ [5] and have the following relationship:

$$
\frac{d^{\alpha} \varepsilon_{s}^{p}}{d N^{\alpha}}=\frac{1}{r p_{a}} q^{\mathrm{av}}
$$

where the shear strain $\varepsilon_{s}^{p}$ is fractionally differentiated by the number of loading cycles $(N)$ instead of the time $t$. This is because in the context of cyclic loading rate means a derivative with respect to the number, $N$. It should be noted that the number of load cycles, $N$, can be related to the real loading time, $t$, by using $t=N / f$ where $f$ denotes the load frequency. Similar approaches can be found elsewhere in [6, 8-10]. $r$ is the shear-related parameter, reflecting the long-term behavior of granular soils. $p_{\mathrm{a}}$ is the atmospheric pressure $(101 \mathrm{kPa})$, for the purpose of parameter dimensionless. Applying Laplace and inverse Laplace transformations to both sides of Eq. (8), yields

$$
d \varepsilon_{s}^{p}=\frac{\alpha q^{\mathrm{av}}}{\Gamma(1+\alpha) r p_{a}} N^{\alpha-1}
$$

Eq. (9) is the ultimate correlation between the cumulative strain $\varepsilon_{s}$ and the loading cycles, $N$. It offers mathematical representation for how the cumulative strain frequently manifests itself through the empirical formula with the form of a power-law function. 


\section{CYCLIC FLOW RULE}

Based on the principle of energy conservation, many different kinds of functions [32-34] describing the static flow for various geomaterials have been deduced, for instance, the Rowe dilatancy equation [32]. However, for granular soils which not only experience particle arrangement but also particle breakage during loading [35]. The energy dissipated by particle breakage for one individual loading process is assumed to be proportional to the energy dissipated by particle arrangement as suggested by McDowell [36]. Therefore, the following energy conservative equation is used:

$$
q d \varepsilon_{s}^{p}+p^{\prime} d \varepsilon_{v}^{p}=M p^{\prime} d \varepsilon_{s}^{p}+M p^{\prime} d \varepsilon_{s}^{p} \frac{M^{a}-\eta^{a}}{\eta^{a}}
$$

where $p^{\prime}\left(=\sigma_{1}^{\prime} / 3+2 \sigma_{3}^{\prime} / 3\right)$ is the mean effective principal stress. The stress ratio $\eta=q / p^{\prime}$. $M\left(=M_{0} p^{b}\right)$ is the critical state friction parameter of the tested material. $M_{0}$ and $b$ are the material constants. It was found that the shear and volumetric strains of soils tested under cyclic loading flows according to a cyclic flow rule [6, 8]. Wichtmann et al. [8-10] proposed a stress dilatancy equation by assuming that the energy was only dissipated by particle slippage. However, as stated before, granular soils not only suffer particle arrangement but also breakage during loading. Therefore, to better reflect the deformation mechanism, a modified cyclic flow rule is suggested here by considering energy dissipation from both particle rearrangement and breakage. For an arbitrary cyclic loading process, the total plastic strain for the tested sample can be expressed as an integral of all the increments in Eq. (10).

$$
\int d \varepsilon_{v}^{p}=M^{a+1} \int \frac{1}{\eta^{a}} d \varepsilon_{s}^{p}-\int \eta d \varepsilon_{s}^{p}
$$

The stress ratio, $\eta$, in Eq. (11) varies with time. However, it can be treated as a mean value, $\eta_{m}$, as suggested by Chang and Wichtmann [37].

$$
\begin{gathered}
\eta_{m}=\frac{\int \eta d \varepsilon_{s}^{p}}{\int d \varepsilon_{s}^{p}} \\
\eta_{m}^{-a}=\frac{\int \eta^{-a} d \varepsilon_{s}^{p}}{\int d \varepsilon_{s}^{p}}
\end{gathered}
$$

Substituting Eqs. (12) and (13) into Eq. (11), one has

$$
\int d \varepsilon_{v}^{p}=\frac{M^{a+1}-\eta_{m}^{a+1}}{\eta_{m}^{a}} \int d \varepsilon_{s}^{p}
$$


By rearranging Eq. (14), the relationship between the cumulative volumetric strain and the the shear strain can be obtained as

$$
\frac{d \varepsilon_{v}^{p}}{d \varepsilon_{s}^{p}} \approx \frac{M^{a+1}-\eta_{m}^{a+1}}{\eta_{m}^{a}}
$$

Eq. (15) can be regarded as a modified cyclic flow rule for granular soils considering the influence of particle breakage. However, the value of the stress ratio, $\eta_{m}$, needs to be determined before the actual use of Eq. (15) in capturing the flow direction of the cumulative strains in granular soils. According to the laboratory observation by Chang and Wichtmann [37], $\eta_{m}$ is slightly larger than the averaged stress ratio, $\eta^{\text {av }}$, in cyclic loading. Therefore, the averaged stress ratio, $\eta^{\text {av }}$, is used instead of the mean value, $\eta_{m}$.

$$
\frac{d \varepsilon_{v}^{p}}{d \varepsilon_{s}^{p}}=\frac{M^{a+1}-\left(\eta^{\mathrm{av}}\right)^{a+1}}{\beta\left(\eta^{\mathrm{av}}\right)^{a}}
$$

where $\beta$ is the material constant, diminishing the influence of the difference between the mean stress ratio, $\eta_{m}$, and the averaged stress ratio, $\eta^{\text {av }}$, on the cyclic flow direction. Fig. 2 shows the comparison of the flow directions predicted by Eq. (16) and the modified Camclay model suggested by Wichtmann et al. [9, 38]. The modified cyclic flow rule takes into account the effect of particle breakage and thus gives better performance than that by Wichtmann et al. [38], especially in the stress dilatant part where the trend of volumetric dilation was reduced by the particle breakage occurred inside the sample.

\section{CONSTITUTIVE EQUATIONS}

The cumulative total strain is a sum of the elastic strain and the plastic strain, which can be formulated as

$$
\begin{aligned}
& d \varepsilon_{v}=d \varepsilon_{v}^{e}+d \varepsilon_{v}^{p} \\
& d \varepsilon_{s}=d \varepsilon_{s}^{e}+d \varepsilon_{s}^{p}
\end{aligned}
$$

where $\varepsilon_{v}^{e}$ and $\varepsilon_{s}^{e}$ are the resilient volumetric and shear strains, respectively. The resilient parts of the total strains can be given as

$$
\begin{gathered}
d \varepsilon_{v}^{e}=\frac{d p^{\mathrm{av}}}{K} \\
d \varepsilon_{s}^{e}=\frac{q^{\mathrm{av}}}{3 G}
\end{gathered}
$$


where the shear modulus $G$ can be defined as [39-40]

$$
G=G_{0} \frac{\left(2.97-e_{0}\right)^{2}}{1+e_{0}} \sqrt{p^{\mathrm{av}} p_{a}}
$$

where $e_{0}$ is the initial void ratio of the sample. $P_{a}=101 \mathrm{kPa}$, is the atmospheric pressure. $G_{0}$ denotes the shear-related modulus for virgin loading; $K$ is the bulk modulus that is expressed as

$$
K=K_{0} \frac{\left(2.97-e_{0}\right)^{2}}{1+e_{0}} \sqrt{p^{\mathrm{av}} p_{a}}
$$

where $K_{0}$ denotes the compression-related modulus for virgin loading;. The cumulative plastic strains caused by cyclic loading can be given as

$$
\begin{gathered}
d \varepsilon_{s}^{p}=\frac{\alpha q^{\mathrm{av}}}{\Gamma(1+\alpha) r p_{a}} N^{\alpha-1} \\
d \varepsilon_{s}^{p}=\frac{M^{a+1}-\left(\eta^{\mathrm{av}}\right)^{a+1}}{\beta\left(\eta^{\mathrm{av}}\right)^{a}} \frac{\alpha q^{\mathrm{av}}}{\Gamma(1+\alpha) r p_{a}} N^{\alpha-1}
\end{gathered}
$$

where parameter $r$ should depend not only on the soil type but also on the stress state and initial physical state. As suggested by $\mathrm{Li}$ et al. [41], it was not convenient to introduce the moisture content and dry density directly into the equation. However, the cyclic strain amplitude of the first loading cycle can indirectly represent the influence of the initial physical state on the cumulative strain of the granular soils. Thus, an empirical formula considering the influence of both stress state and initial physical state of soils is suggested as

$$
r=D\left(\eta^{\text {av }}\right)^{m}\left(\varepsilon^{\text {ampl }}\right)^{n}
$$

where $D, m, n$, are material constants and the cyclic strain amplitude, $\varepsilon^{\text {ampl }}$, can be obtained by using

$$
\varepsilon^{\mathrm{ampl}}=\frac{\Delta q}{G} \frac{1}{1-\frac{2 \Delta q}{\Delta q_{\max }}}
$$

where $\Delta q$ and $\Delta q_{\max }$ denote the cyclic amplitude of the deviator stress and the distance away from the failure envelop, respectively, as illustrated in Fig. 1. Note that $\Delta p^{\prime}$ and $p^{\text {av }}$ in Fig. 1 are the cyclic amplitude of the mean principal stress and the averaged mean principal stress, respectively. 

can be determined by static and cyclic triaxial tests. The moduli $K_{0}$ and $G_{0}$ can be obtained by resonant column test or measuring the initial stress-strain of the sample subjected to triaxial loading. The critical state friction parameter $M_{0}$ and $b$ related to the gradient of the critical state stress in the $p-q$ space and can be obtained by static triaxial test. The critical state stress along with the peak stress envelop of railroad ballast, as shown in Fig. 3 varies with the initial confining pressures which is different from that of sand [42-43]. This can be partially attributed to the particle breakage during sample preparation which changed the initial particle size distribution of the railroad ballast. The critical stress ratio, $M$, depends on the effective mean principal stress [43-45]. An increase of stress level leads to an increase of the particle breakage [46-48]. Therefore, a varying critical stress ratio as suggested by Xiao et al. [43] is used. However, the critical state friction angle for sand [10] is taken as constant here. Parameters $a$ and $\beta$ define the flow direction of sand under cyclic loading and can be determined by adjusting the value of $\beta$ to obtain a better correlation between $\ln \left(d \varepsilon_{v}^{p} / d \varepsilon_{s}^{p}+\eta^{\text {av }} / \beta\right)$ and $\ln \left(\eta^{\text {av }}\right)$, where the value of $a$ can be obtained by measuring the slope of the corresponding fitting line, as illustrated in Fig. 4. The fractional derivative order, $\alpha$, describes the rate of strain accumulation and is independent of the deviator stress according to the research by $\mathrm{Li}$ et al. [41]. Therefore, it can be determined by fitting the relationship between the shear strain, $\varepsilon_{s}^{p}$, and the number of loading cycles, $N$. Note that sometimes the cumulative strain used to calculate the exponent, $\alpha$, as illustrated in Fig. 5, is the cumulative total strain rather than the cumulative plastic strain. This is considered acceptable because the resilient/elastic strain will become nearly constant and negligible when compared with the plastic strain after a certain number of loading cycles. Parameters $D$, $m$, and $n$ can be obtained by regression with the value of $r$ (Fig. 6) which is related to the plastic strain of the first loading cycle. To show the advantage of the present model in simulating the cumulative deformation, the prediction of the mathematical model proposed by François et al. [46] is also provided for comparison. The model contains 10 parameters (Table 1) that depend on the value of the cyclic stress amplitude. As suggested by François et al. [49], the model parameters need to be determined by nonlinear least squares method. Detailed values of the model parameters can be found in Table 1.

\section{MODEL PERFORMANCE}

It was found that the stress amplitude had significant influence on the cyclic deformation of granular soils in the long run [8-10]. To validate the proposed mathematical model, test results of four different granular soils, as shown in Table 2, are used. The natural quartz sand was taken from a sand pit near Dorsten, Germany [10]. The grain shape is sub-angular and the specific weight along with the other physical properties can be found in Table 2. The samples were tested under different drained cyclic triaxial loading conditions with the averaged mean principal stress equal $200 \mathrm{kPa}$ and the averaged deviator stresses equal to 50 $\mathrm{kPa}, 100 \mathrm{kPa}, 150 \mathrm{kPa}, 175 \mathrm{kPa}$, and $225 \mathrm{kPa}$. Each loading condition had the same cyclic stress amplitude $q^{\mathrm{ampl}}$, equal to $40 \mathrm{kPa}$, and the same loading frequency, equal to $1 \mathrm{~Hz}$. Fig. 7 
shows the model simulation of the cumulative deformations of natural quartz sand [10]. The cumulative strain increased with the increase of the applied average stress ratio. It is observed that the mathematical model can well capture both the long-term shear strain and volumetric strain under different deviator stresses. It can also give satisfactory predictions of the initial deformations for several test conditions. However, if more different complicated loading conditions involved, this model indeed loses some ability in accurately predicting the deformation at the initial loading stage, for example, test result with higher stress ratio. This is because this model aims at predicting the long-term cumulative deformation rather than the short-term stress strain response of the sample. However, this shortcoming can be resolved by using variable fractional derivative order but is not within the scope of current research. To the author's knowledge, the fractional derivative order could depend on the mechanical state, such as the loading stress and strain, etc. [27-29]. But, the use of the variable order may involve significantly complex mathematic calculations (see [27] for instance), which is not applicable for the engineering concern. The predictions of the numerical model, denoted as François model [46], are also provided for comparison. As shown in Fig. 7, it can only give comparatively good predictions of the soil deformation under low stress ratios. In contrast, the proposed model exhibits better potential in characterising the cumulative deformation of the natural quartz sand under both low and high stress ratios.

The railroad ballast was a kind of crushed basalt, collected from Bombo quarry near Wollongong, New South Wales, Australia. It was an angular/subangular volcanic latite basalt that contains the primary minerals feldspar, plagioclase, and augite [42]. Its physical attributes can be found in Table 2. The railroad ballast was tested under the confining pressures equal to $10 \mathrm{kPa}, 60 \mathrm{kPa}, 120 \mathrm{kPa}$ with two different cyclic stress amplitudes equal to $185 \mathrm{kPa}$ and $455 \mathrm{kPa}$. The sample was prepared by tamping to $300 \mathrm{~mm}$ in diameter and $600 \mathrm{~mm}$ in height before tested under a loading frequency equal to $20 \mathrm{~Hz}$. Fig. 8 shows the comparison between the test results and the predicted results by the proposed model as well as the François model. It is observed from Fig. 8(a) that the proposed model can well capture the cumulative shear strain of ballast tested under different confining and deviator stresses. The cumulative shear strain increased with increasing confining pressure. Larger deviator stress resulted in larger cumulative shear strain given the same confining pressure. Moreover, through the incorporation of the modified cyclic flow rule, the proposed model can well characterize both the volumetric dilatancy under low confining pressure and the volumetric contraction under relatively high confining pressure, as shown in Fig. 8(b). But in contrast, the François model can only give satisfactory predictions of the shear strains under low confining pressure and the volumetric strains under high confining pressure. Most importantly, the model parameters are highly dependent on the cyclic amplitude. Therefore, the proposed model exhibits a better flexibility in modelling the long-term deformation of different granular soils tested under different loading conditions.

Moreover, to preliminarily demonstrate the ability of the fractional order model in characterising the entire stress strain hysteresis curve, two additional cyclic tests, as shown in Figs. 9 and 10, are simulated by using Eq (7). Fig. 9 shows the prediction of the drained cyclic triaxial tests on the Zipingpu rockfill [14]. The sample was prepared to have a diameter 
equal to $300 \mathrm{~mm}$ and a height equal to $600 \mathrm{~mm}$ before initially compressed to an effective mean principal stress equal to $500 \mathrm{kPa}$. The subsequent test was conducted under the stress amplitude equal to $400 \mathrm{kPa}$. The physical properties of the sample can be found in Table 2 . The shear-related moduli, $G_{0}$, used for first, second loading and the subsequent unloading are 15.5 MPa, 9.7 MPa, 7.0 MPa, respectively. The compression-related moduli, $K_{0}$, used for first, second loading and the subsequent unloading are 42.3 $\mathrm{MPa}$, 5.5 $\mathrm{MPa}$, and 1.0 $\mathrm{MPa}$, respectively. The fractional order $\alpha$ is found to be 0.71 . It is observed from Fig. 9(a) that the proposed approach can well represent the virgin loading and unloading of the Zipingpu rockfill. The subsequent hysteresis loops between the axial strain and the deviator stress can be also characterised. However, as shown in Fig. 9(b), the proposed model can only simulate the increase of the volumetric strain during virgin loading. The subsequent variation cannot be well simulated. Fig. 10 shows the prediction of the trixial test results performed on a dense rockfill [22] which consisted of mainly weathered quartz monzonite. The triaxial test was performed on a $300 \mathrm{~mm}$ diameter and $700 \mathrm{~mm}$ high specimen. The initial effective mean principal stress was equal to $3 \mathrm{MPa}$ and the subsequent loading amplitude was 2MPa with a loading frequency equal $0.1 \mathrm{~Hz}$. Detailed physical properties of the Toyoura sand can be found in Table 2. The shear-related moduli, $G_{0}$, used for first, second loading and the subsequent unloading are 32 MPa, 7.1 MPa, 9.5 MPa, respectively. The compression-related moduli, $K_{0}$, used for first, second, loading and the subsequent unloading are 5.82 MPa, 4.0 $\mathrm{MPa}$, and $0.58 \mathrm{MPa}$, respectively. The fractional order $\alpha=0.81$. Once again, a well representation of the stress strain hysteresis can be observed from Fig. 10(a). But the predicted volumetric strain is relatively higher than the experimental results. Further modification of the current model needs to be conducted in order to accurately capture the variation of the volumetric strain during cyclic loading.

(1)

2

\section{CONCLUSIONS}

A fractional order model was presented to simulate the cumulative deformation of granular soils subjected to cyclic loading. This model consists of two main parts. Firstly, a fractional derivative was used to derive the power law connection between the cumulative shear strain and its loading cycles. Then, an energy based approach was employed to provide a modified cyclic flow rule particularly for crushable granular soils. The modified the flow rule took into account the particle breakage of granular soils under cyclic loading thus had a better potential in characterizing the cyclic flow direction of granular soils. All the model parameters can be determined from the cyclic and static triaxial tests. It is noted that the physical origins of several parameters are not clear and still need further investigation. To validate the proposed model, predicted and measured results for several different granular soils, i.e., sand, rockfill, and railroad ballast, were simulated. The proposed model was also compared with an existing cumulative model to demonstrate its advantage in modelling longterm deformation of granular soils. It was observed that with the help of the fractional derivative theory, the distinct power law evolution between the shear strain and the corresponding loading cycle under different loading conditions was reasonably captured. Besides, by employing the modified cyclic flow rule, the model was also able to predict both 
the volumetric compression under relatively high confining pressure and the volumetric dilatancy under low confining pressure. It is thus concluded that the proposed model could well capture both the cumulative shear strain and the cumulative volumetric strain of granular soils. Moreover, to preliminary demonstrate the fractional order approach in modelling the stress strain hysteresis during cyclic loading, two additional simulations of the triaxial test results performed on rockfill were also provided. The fractional order approach was shown to have great potential in modelling the entire stress and strain curve of rockfill during cyclic loading. However, this model cannot accurately represent the variation of the volumetric deformation. Further modifications still need be conducted.

\section{ACKNOWLEDGEMENTS}

The authors would like to thank Professor W. Chen and Dr Xiaodi Zhang in Hohai University for their kind instructions on several fundamentals of the fractional calculus. The financial supports provided by the Fundamental Research Funds for the Central Universities (Grant No. 106112015CDJXY200008) is also greatly appreciated.

(1)

[1] Miura,N., Fujikawa,K., Sakai,A. and Hara,K. Field measurement of settlement in saga airport highway subjected to trafficload. Tsuchi-to-Kiso, 1995, 43-6(449): 49-51.

[2] Ren,X.W., Tang,Y.Q., Li,J. and Yang,Q. A prediction method using grey model for cumulative plastic deformation under cyclic loads. Natural Hazards, 2012, 64(1): 441-457.

[3] Li,D.Q. and Selig,E.T. Cumulative plastic deformation for tine grained subgrade soils. Journal of Geotechnical Engineeing ASCE, 1996, 122(12): 1006-1013.

[4] Chai,J.C. and Miura,N. Traffic-load-induced permanent deformation of road on soft subsoil. Journal of Geotechnical and Geoenvironmental Engineering, 2002, 128(11): 907916.

[5] Bouckovalas,G., Whitman,R.V. and Marr,W.A. Permanent displacement of sand with cyclic loading. Journal of Geotechnical Engineeing ASCE, 1984, 110(11): 1606-1623.

[6] Suiker,A.S.J. and de,Borst,R. A numerical model for the cyclic deterioration of railway tracks. International Journal for Numerical Methods in Engineering, 2003, 57(4), 441470.

[7] Khalili,N., Habte,M. and Valliappan,S. A bounding surface plasticity model for cyclic loading of granular soils. International Journal for Numerical Methods in Engineering, 2005, 63(14), 1939-1960.

[8] Niemunis,A., Wichtmann,T. and Triantafyllidis,T.H. A high-cycle accumulation model for sand. Computer and Geotechnics, 2005, 32(4): 245-263.

[9] Wichtmann,T., Niemunis,A. and Triantafyllidis,T.H. Experimental evidence of a unique flow rule of non-cohesive soils under high-cyclic loading. Acta Geotechnica, 2006, 1(1): 59-73. 
[10] Wichtmann,T., Niemunis,A. and Triantafyllidis,T.H. Validation and calibration of a highcycle accumulation model based on cyclic triaxial tests on eight sands. Soils and Foundations, 2009, 49(5), 711-728.

[11] Li,S., and Huang,M. Undrained long-term cyclic degradation characteristics of offshore soft clay. In Proceedings of the GeoShanghai 2010 International Conference, Shanghai, China. Huang M S, Yu X, Huang Y, eds. 2010. 263-271.

[12] Li,L.L., Dan,H.B. and Wang,L. Z. Undrained behavior of natural marine clay under cyclic loading, Ocean Engineering, 2011, 38(16): 1792-1805.

[13] Karim,M.R., Oka,F., Krabbenhoft,K., Leroueil,S. and Kimoto,S. Simulation of long-term consolidation behavior of soft sensitive clay using an elasto-viscoplastic constitutive model. International Journal for Numerical and Analytical Methods in Geomechanics, 2013, 37(16): 2801-2824.

[14] Liu,H., Zou,D. and Liu,J. Constitutive modeling of dense gravelly soils subjected to cyclic loading. International Journal for Numerical and Analytical Methods in Geomechanics, 2014, DOI: 10.1002/nag.2269.

[15] Seidalinov,G. and Taiebat,M. Bounding surface SANICLAY plasticity model for cyclic clay behavior. International Journal for Numerical and Analytical Methods in Geomechanics, 2014, 38(7): 702-724.

[16] Ishikawa,T., Sekine,E. and Miura,S. Cyclic deformation of granular material subjected to moving-wheel loads. Canadian Geotechnical Journal, 2011, 48(5): 691-703.

[17] Suiker,A.S.J, Selig,E.T. and Frenkel,R. Static and cyclic triaxial testing of ballast and subballast. Journal of Geotechnical and Geoenvironmental Engineering, 2005, 131(6): 771-782.

[18] Indraratna,B., Lackenby,J. and Christie,D. Effect of confining pressure on the degradation of ballast under cyclic loading. Géotechnique, 2005, 55(4): 325-328.

[19] Lackenby,J., Indraratna,B., McDowell,G. and Christie,D. Effect of confining pressure on ballast degradation and deformation under cyclic triaxial loading. Géotechnique, 2007, 57(6): 527-536.

[20] Indraratna,B., Thakur,P.K. and Vinod,J.S. Experimental and numerical study of railway ballast behavior under cyclic loading. International Journal of Geomechanics, 2009, 10(4): 136-144.

[21] Xiao,Y., Liu,H., Chen,Y. and Jiang,J. Bounding surface model for rockfill materials dependent on density and pressure under triaxial stress conditions. Journal of Engineering Mechanics, 2014, 140(4), 04014002. doi: 10.1061/(ASCE)EM.1943-7889.0000702.

[22] Fu,Z., Chen,S. and Peng,C. Modeling cyclic behavior of rockfill materials in a framework of generalized plasticity.International Journal of Geomechanics, 2014, 14(2): 191-204.

[23] Ling,H.I. and Yang,S. Unified sand model based on the critical state and generalized plasticity. Journal of Engineering Mechanics, 2006, 132(12): 1380-1391.

[24] Indraratna,B., Thakur,P.K., Vinod,J.S. and Salim,W. Semi-empirical cyclic densification model for ballast incorporating particle breakage. International Journal of Geomechanics, 2012, 12(3): 260-271.

[25] Chrismer,S. and Selig,E.T. Computer model for ballast maintenance planning. In Proceedings of 5th International Heavy Haul Railway Conference, Beijing, China. 1993, 223-227. 
[26] Indraratna,B., Salim,W., Ionescue,D. and Christie,D. Stress-strain and degradation behavior of railway ballast under static and dynamic loading, based on large-scale triaxial testing. In Proceedings of 15th international conference on soil mechanics and geotechnical engineering, Istanbul, Turkey, 2001, 2093-2096.

[27] Sun,H.G., Chen,W. and Chen,Y.Q. Variable-order fractional differential operators in anomalous diffusion modeling, Physica A, 2009, 388(21): 4586-4592.

[28] Sun,Y., Liu,H., Xiao,Y. Gao,H. and Cui,Y. Modeling of rheological behavior of geomaterials based on fractional viscoelastic equation with variable parameters. In Proceedings of GeoHunan international conference 2011, Hunan, China. Ge L, Zhang X, Wu J, Correia A G, eds. 2011. 107-114.

[29] Yin,D., Wu,H., Cheng,C. and Chen,Y.Q. Fractional order constitutive model of geomaterials under the condition of triaxial test. International Journal for Numerical and Analytical Methods in Geomechanics, 2013, 37(8): 961-972.

[30] Yin,D., Duan,X. and Zhou,X. Fractional time-dependent deformation component models for characterizing viscoelastic Poisson's ratio. European Journal of Mechanics A/Solids, 2013, 42: 422-429.

[31] Kilbas,A.A.A, Srivastava,H.M. and Trujillo,J.J. Theory and applications of fractional differential equations. Elsevier Science Limited, 2006. 91-99.

[32] Rowe,P.W. The stress-dilatancy relation for static equilibrium of an assembly of particles in contact. Proceedings of Royal Society of London A Mathematical and Physical Science, 1962, 269(1339): 500-527.

[33] Indraratna,B. and Salim,W. Modelling of particle breakage of coarse aggregates incorporating strength and dilatancy. Proceedings of ICE Geotechnical Engineering, 2002, 155(4): 243-252.

[34] Sun,Y., Liu,H. and Yang,G. Yielding function for coarse aggregates considering gradation evolution induced by particle breakage. Rock and Soil Mechanics, 2013, 34(12): 3479_ 3484.

[35] Liu,H., Sun,Y., Yang,G. and Chen,Y. A review of particle breakage characteristics of coarse aggregates. Journal of Hohai University (Natural Sciences). 2012, 40(4): 361-369. (in Chinese).

[36] McDowell,G.R. A family of yield loci based on micro mechanics. Soils and Foundations, 2000, 40(6): 133-137.

[37] Chang,C.S and Whitman,R.V. Drained permanent deformation of sand due to cyclic loading. Journal of Geotechnical Engineeing ASCE, 1988, 114(10): 1164-1180.

[38] Wichtmann,T., Niemunis,A.and Triantafyllidis,T.H. Flow rule in a high-cycle accumulation model backed by cyclic test data of 22 sands. Acta Geotechnica, 2014, 1-15.

[39] Richart,F.E.Jr, Hall,J.R. and Woods,R.D. Vibrations of soils and foundations. Englewood Cliffs, NJ: Prentice-Hall, 1970.

[40] Li,X. and Dafalias,Y. Dilatancy for cohesionless soils. Géotechnique, 2000, 50(4), 449460.

[41] Li,D. and Selig,E.T. Cumulative plastic deformation for fine-grained subgrade soils. Journal of Geotechnical Engineeing ASCE, 1996, 122(12): 1006-1013. 
[42] Lackenby,J. Triaxial behaviour of ballast and the role of confining pressure under cyclic loading. Dissertation for the Doctoral Degree. Wollongong: University of Wollongong, 2006. 89-91.

[43] Xiao,Y., Liu,H., Chen,Y., Jiang,J., and Zhang,W. State-dependent constitutive model for rockfill materials. International Journal of Geomechanics, 2014, 04014075 . doi: 10.1061/(ASCE)GM.1943-5622.0000421.

[44] Indraratna,B., Wijewardena,L.S.S. and Balasubramaniam,A.S. Large-scale triaxial testing of greywacke rockfill. Géotechnique, 1993, 43(1), 37-51.

[45] Frossard,E., Dano,C., Hu,W., and Hicher,P.Y. Rockfill shear strength evaluation: a rational method based on size effects. Géotechnique, 2012, 62(5), 415-427.

[46] Xiao,Y., Liu,H., Chen, Y., and Jiang,J. Bounding Surface Plasticity Model Incorporating the State Pressure Index for Rockfill Materials. Journal of Engineering Mechanics, 2014, 140(11), 04014087. doi: 10.1061/(ASCE)EM.1943-7889.0000802.

[47] Xiao,Y., Liu,H., Chen,Y., Jiang,J. and Zhang,W. Testing and modeling of the statedependent behaviors of rockfill material. Computers and Geotechnics, 61(9), 153-165.

[48] Xiao,Y., Sun,Y., and Hanif,F. A particle-breakage critical state model for rockfill material. Science China Technological Sciences, 58(7), 1125-1136.

[49] François,S., Karg,C., Haegeman,W., and Degrande,G. A numerical model for foundation settlements due to deformation accumulation in granular soils under repeated small amplitude dynamic loading. International Journal for Numerical and Analytical Methods in Geomechanics, 2010, 34(3): 273-296. 


\section{Table caption list:}

Table 1 Model parameters

Table 2 Physical properties of the granular soils 
Table 1. Model parameters

\begin{tabular}{|c|c|c|c|c|}
\hline Model & Parameters & $\begin{array}{c}\text { Natural quartz } \\
\text { sand [10] }\end{array}$ & \multicolumn{2}{|c|}{ Railroad ballast [42] } \\
\hline \multirow{11}{*}{ Current model } & $q^{\mathrm{ampl}}(\mathrm{kPa})$ & 40 & 185 & 455 \\
\hline & $G_{0}(\mathrm{kPa})$ & 230 & 383 & 383 \\
\hline & $K_{0}(\mathrm{kPa})$ & 213 & 355 & 355 \\
\hline & $M$ & 1.28 & 4.66 & 4.66 \\
\hline & $b$ & 0 & 0.82 & 0.82 \\
\hline & $a$ & 1.64 & 1.8 & 1.8 \\
\hline & $\alpha$ & 0.15 & 0.1 & 0.1 \\
\hline & $\beta$ & 0.55 & 1.0 & 1.0 \\
\hline & $D$ & 1477.34 & 318.8 & 318.8 \\
\hline & $m$ & 0.56 & -1.1 & -1.1 \\
\hline & $n$ & -0.21 & -0.72 & -0.72 \\
\hline \multirow{10}{*}{ François model [49] } & $\alpha_{f}\left(10^{-4}\right)$ & 0.007 & 7.4 & 2.6 \\
\hline & $\beta_{f}\left(10^{-6}\right)$ & -0.07 & -5.4 & -21.8 \\
\hline & $\eta_{f}$ & 700 & 105.9 & 7.0 \\
\hline & $d_{f}$ & 0.25 & 0.01 & 0.01 \\
\hline & $\alpha_{c}\left(10^{-4}\right)$ & 0.04 & 8.0 & 0.56 \\
\hline & $\beta_{c}\left(10^{-6}\right)$ & -0.02 & -78 & -3.4 \\
\hline & $\eta_{c}$ & 700 & 1.1 & 85.7 \\
\hline & $C_{p}\left(\mathrm{~Pa}^{-1}\right)$ & 0.005 & 0.007 & 0.007 \\
\hline & $K_{r e f}$ & 213 & 355 & 355 \\
\hline & $v$ & 0.2 & 0.2 & 0.2 \\
\hline
\end{tabular}

Table 2. Physical properties of the granular soils

\begin{tabular}{ccccc}
\hline Materials & $\begin{array}{c}\text { Natural quartz } \\
\text { sand [10] }\end{array}$ & $\begin{array}{c}\text { Zipingpu rockfill } \\
{[14]}\end{array}$ & $\begin{array}{c}\text { Weathered } \\
\text { monzonite [22] }\end{array}$ & $\begin{array}{c}\text { Railroad ballast } \\
{[42]}\end{array}$ \\
\hline$G_{s}$ & 2.65 & - & 2.71 & 2.66 \\
\hline$d_{50}(\mathrm{~mm})$ & 0.35 & 9.5 & 18 & 39.5 \\
\hline$C_{u}$ & 1.9 & - & 11 & 1.53 \\
\hline$e_{\max }$ & 0.930 & - & 0.3 & 0.97 \\
\hline$e_{\min }$ & 0.544 & - & 0.15 & 0.67 \\
\hline$e_{0}$ & 0.745 & 0.313 & 0.17 & 0.74 \\
\hline
\end{tabular}




\section{Figure caption list:}

Fig. 1. Schematic representation of the cyclic triaxial test

Fig. 2. Cyclic flow rule

Fig. 3. Critical state line and peak stress line

Fig. 4. Determination of parameters $a$ and $\beta$

Fig. 5. Determination of exponent $\alpha$

Fig. 6. Determination of parameters $D, m$ and $n$

Fig. 7. Model predictions of the cumulative deformation of natural quartz sand [10]

Fig. 8. Model predictions of the cumulative deformation of railroad ballast [42]

Fig. 9. Representation of the stress strain behaviour of Zipingpu rockfill [14]

Fig. 10. Representation of the stress strain behaviour of weathered monzonite [22] 


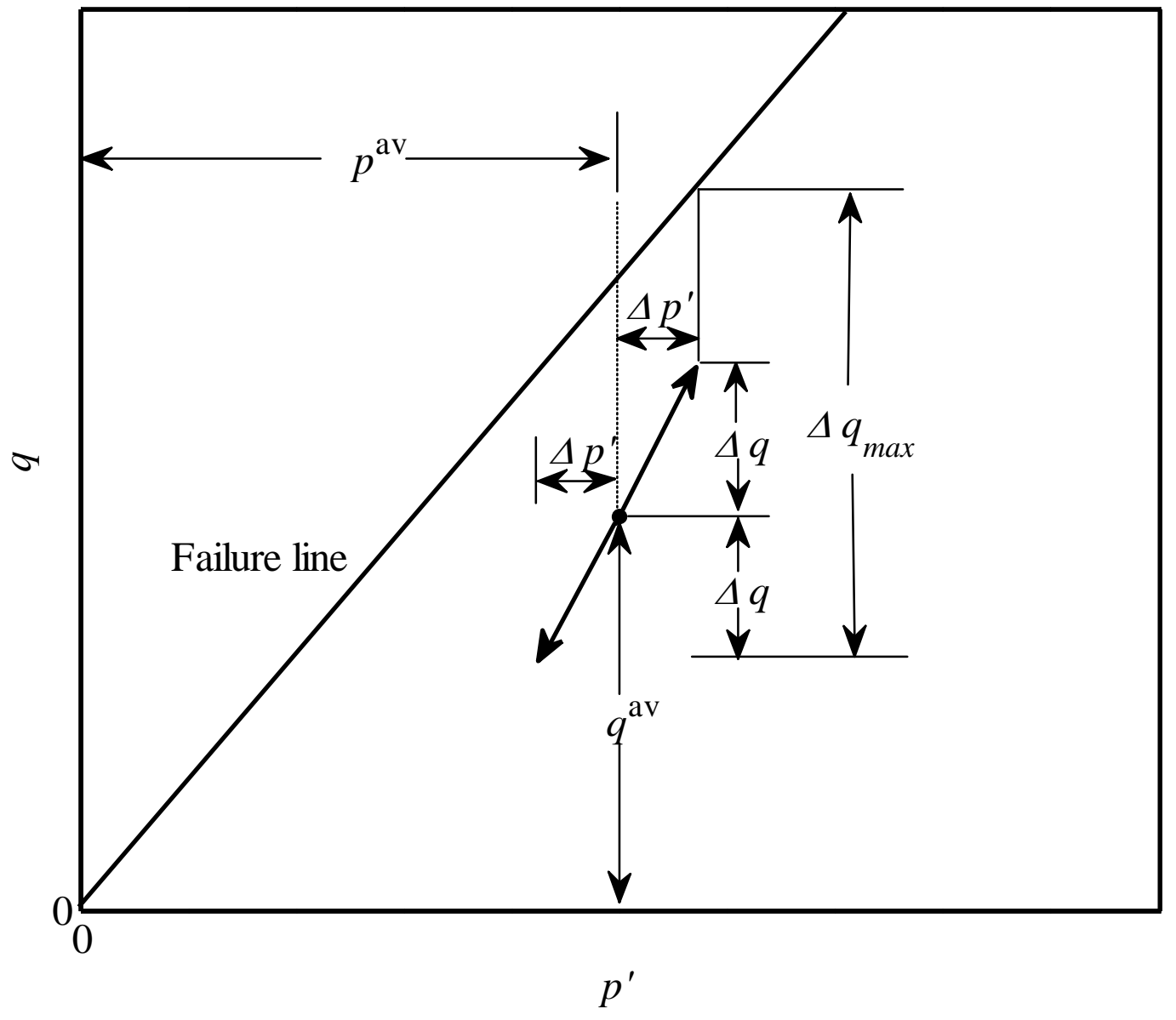

Fig. 1. Schematic representation of the cyclic triaxial test 


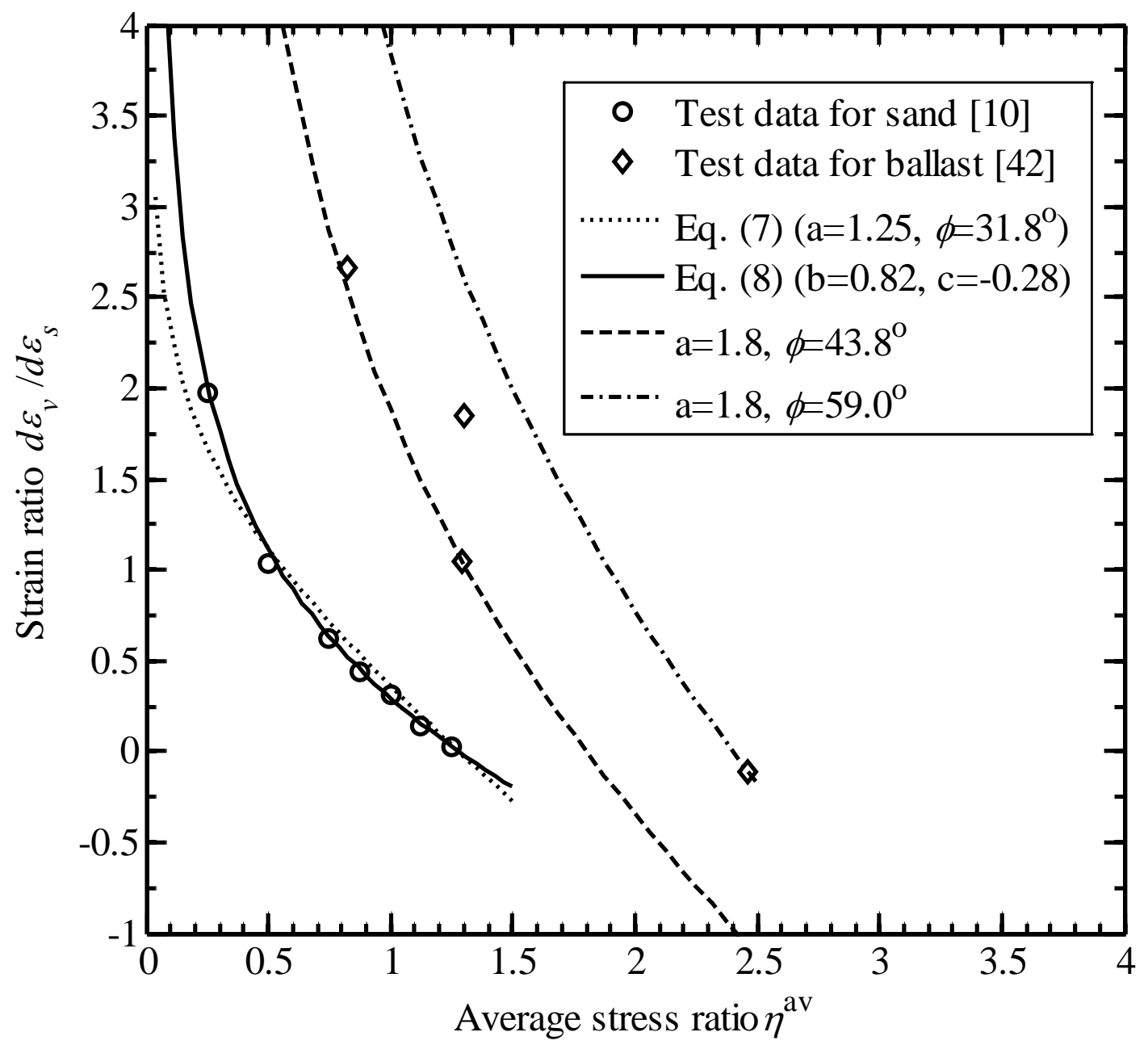

Fig. 2. Cyclic flow rule 


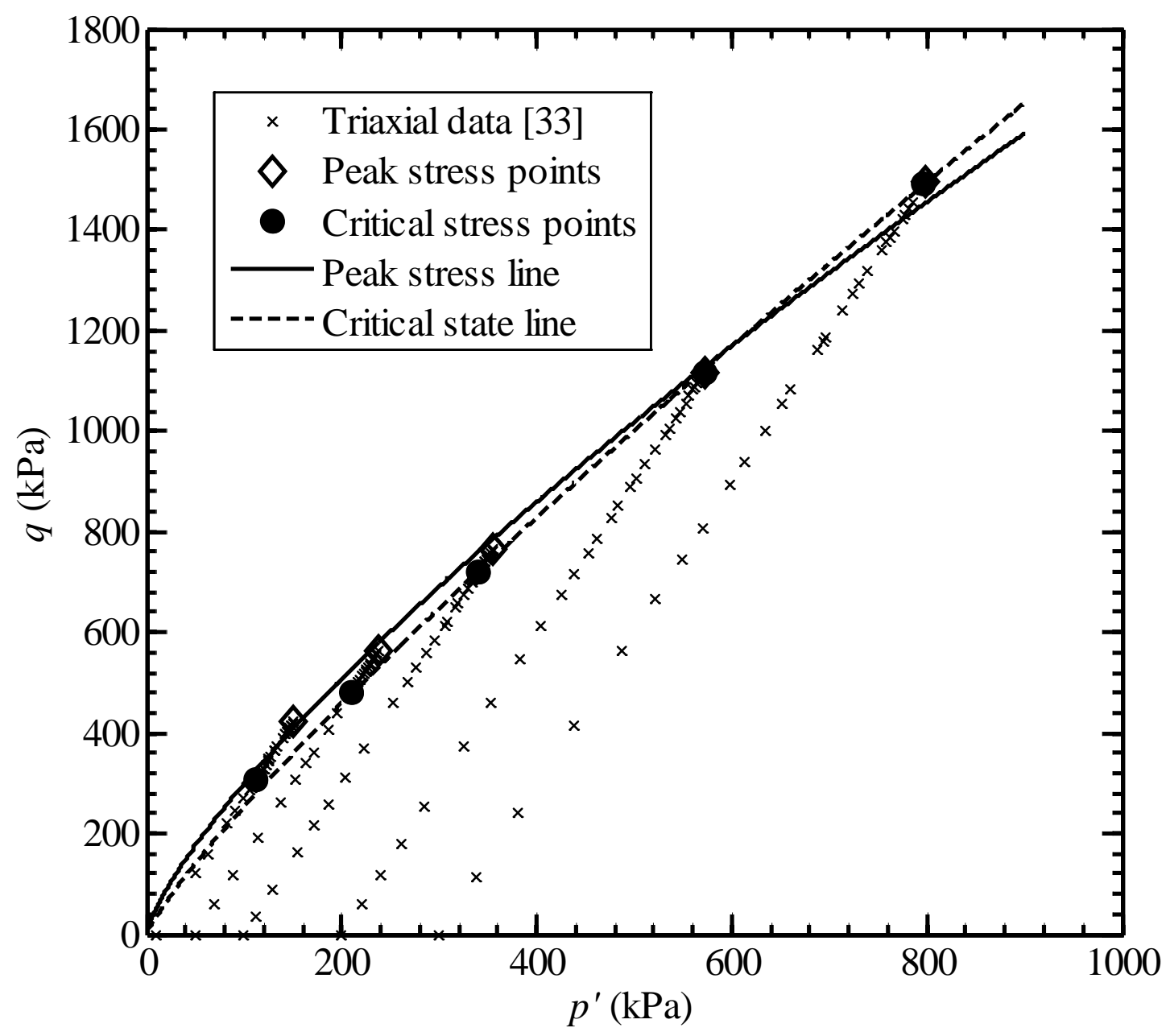

Fig. 3. Critical state line and peak stress line 


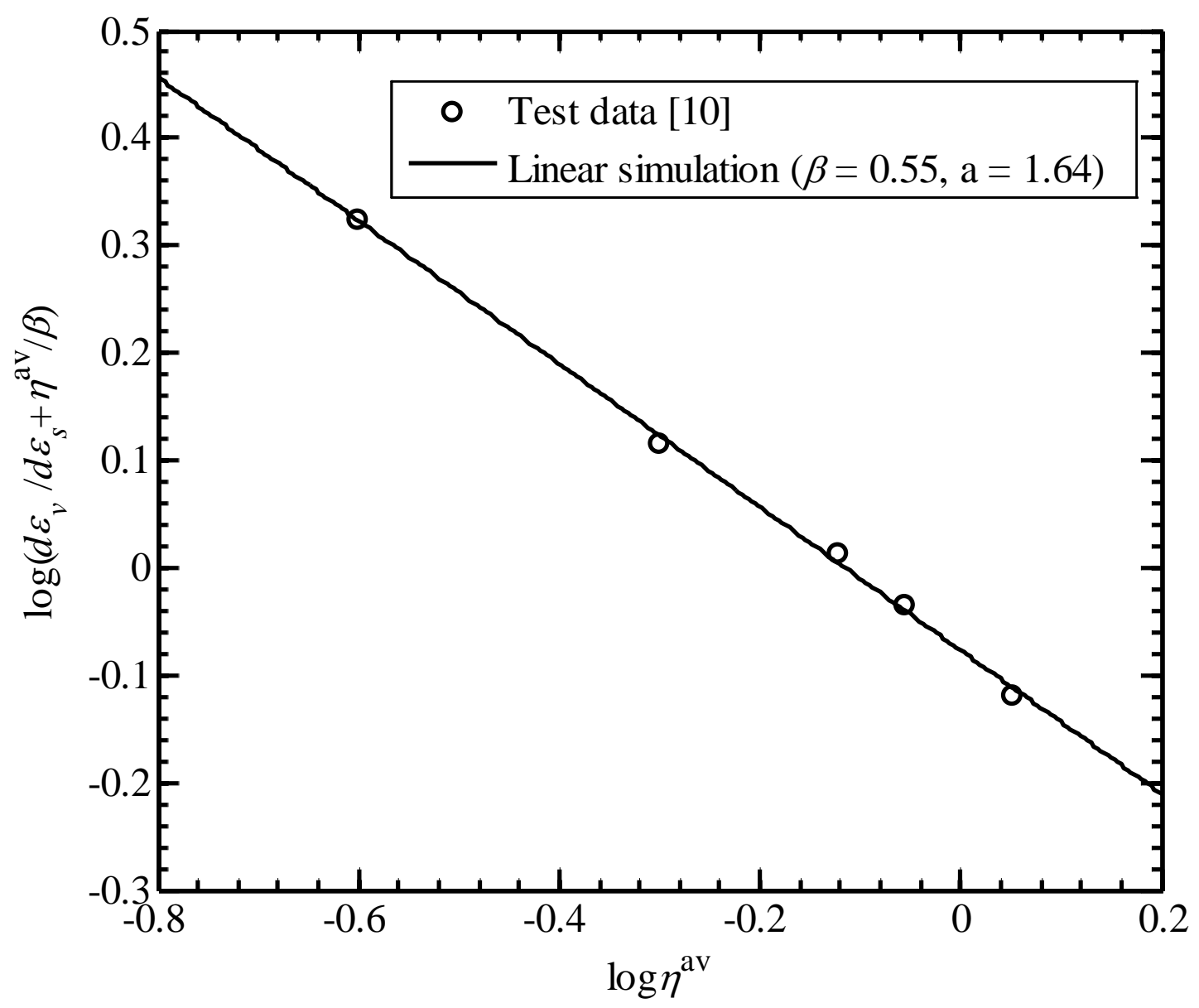

Fig. 4. Determination of parameters $a$ and $\beta$ 


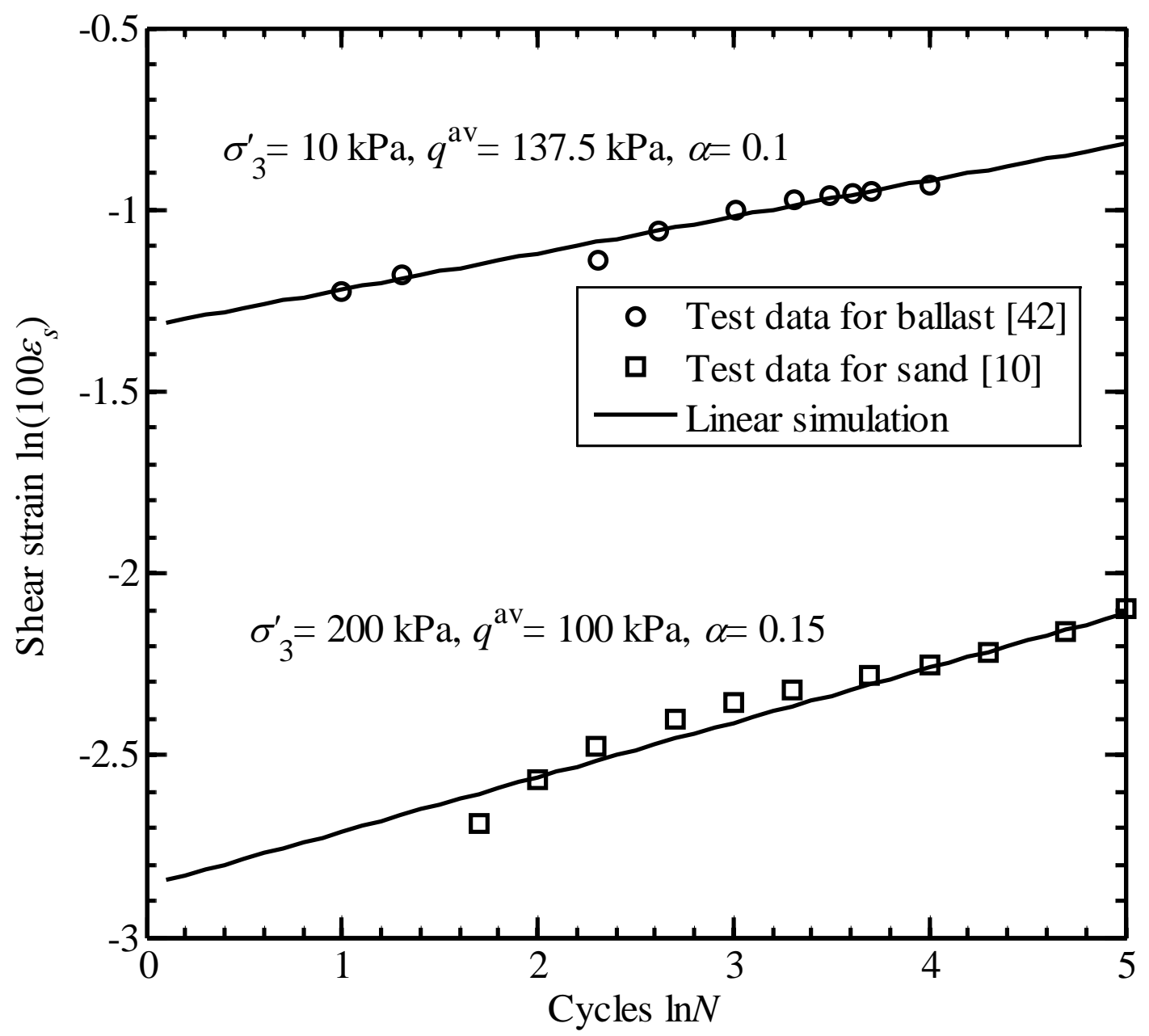

Fig. 5. Determination of exponent $\alpha$ 


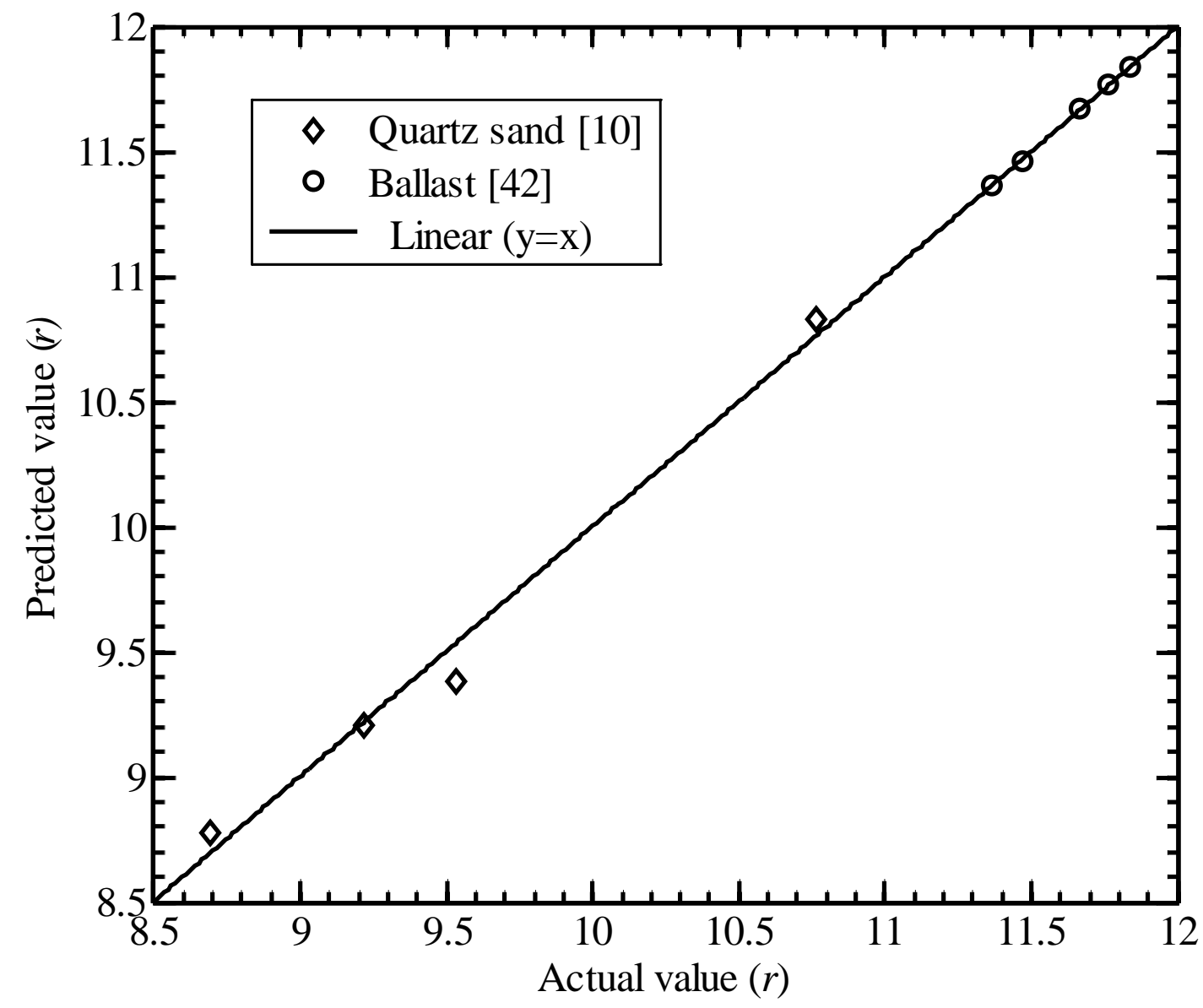

Fig. 6. Determination of parameters $D, m$ and $n$ 


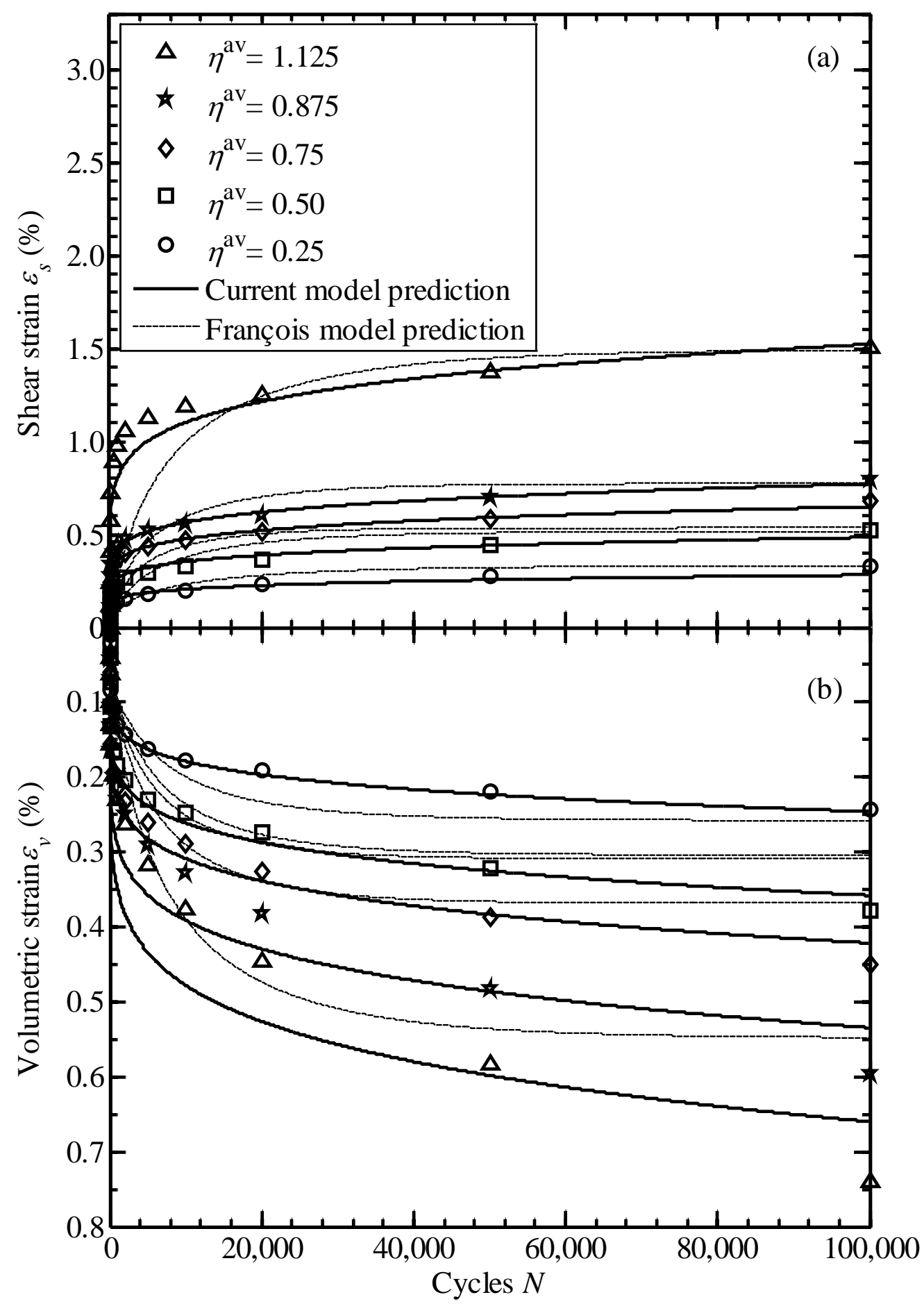

Fig. 7. Model predictions of the cumulative deformation of natural quartz sand [10] 


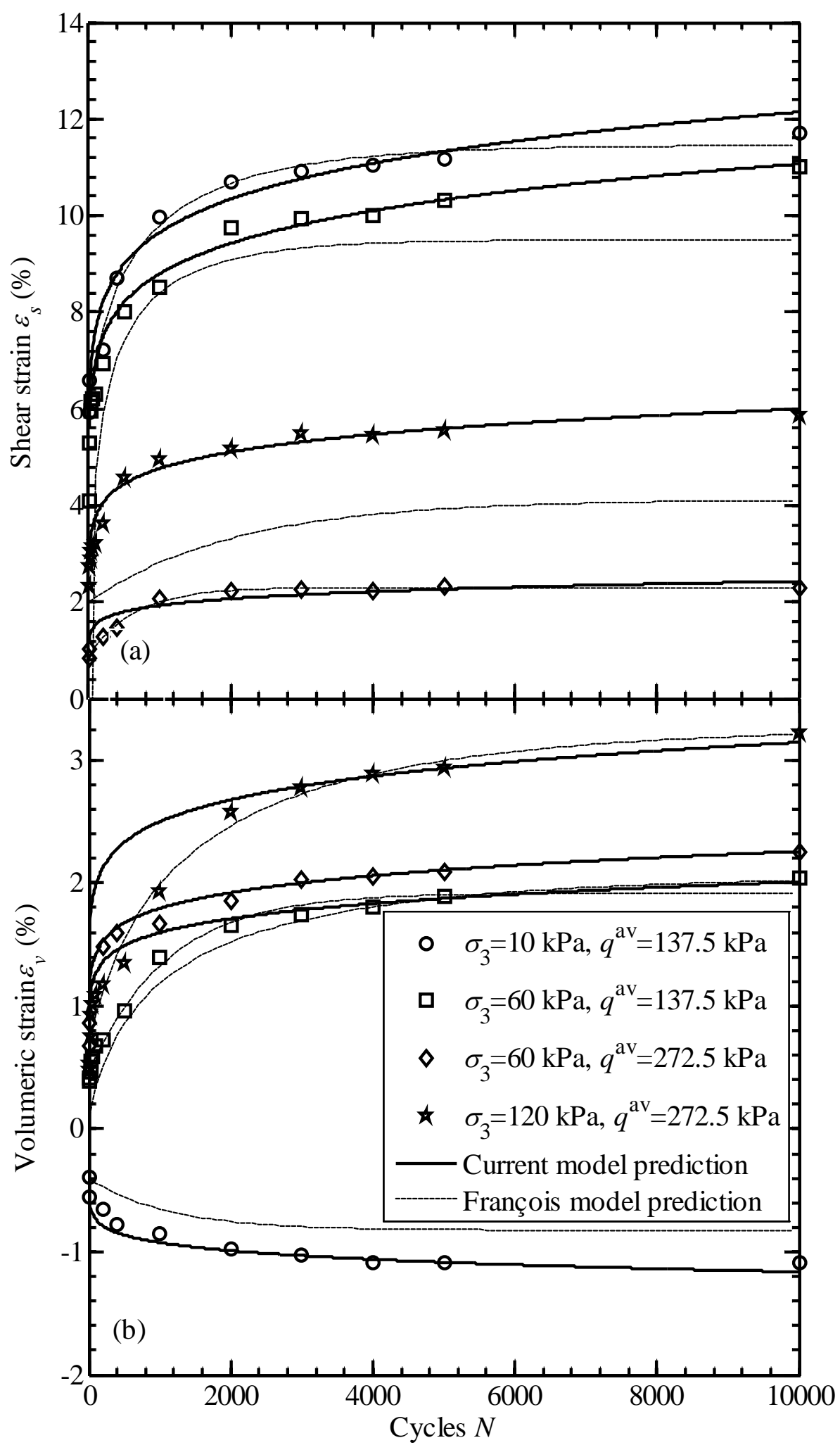

Fig. 8. Model predictions of the cumulative deformation of railroad ballast [42] 


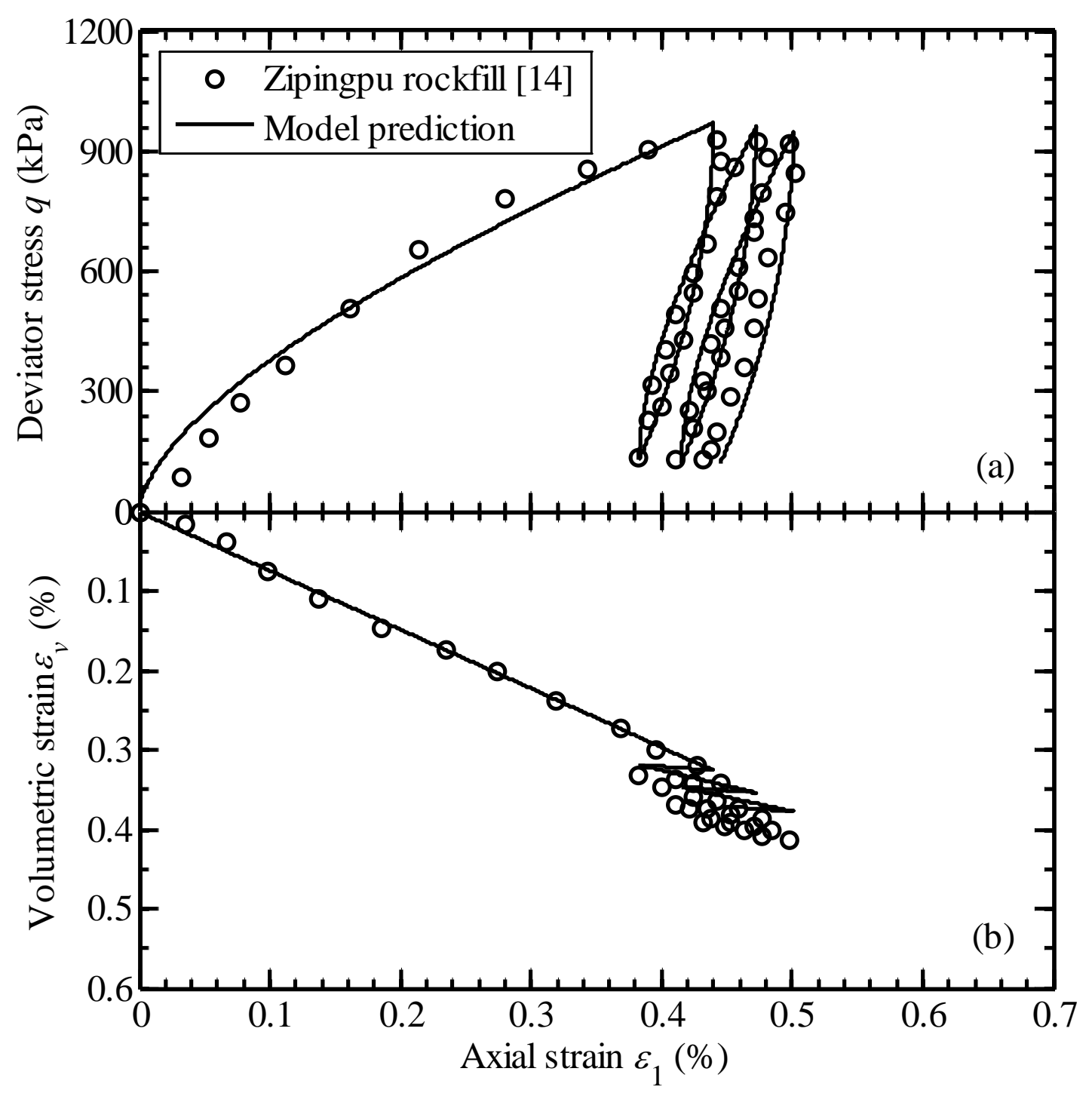

Fig. 9. Representation of the stress strain behaviour of Zipingpu rockfill [14] 


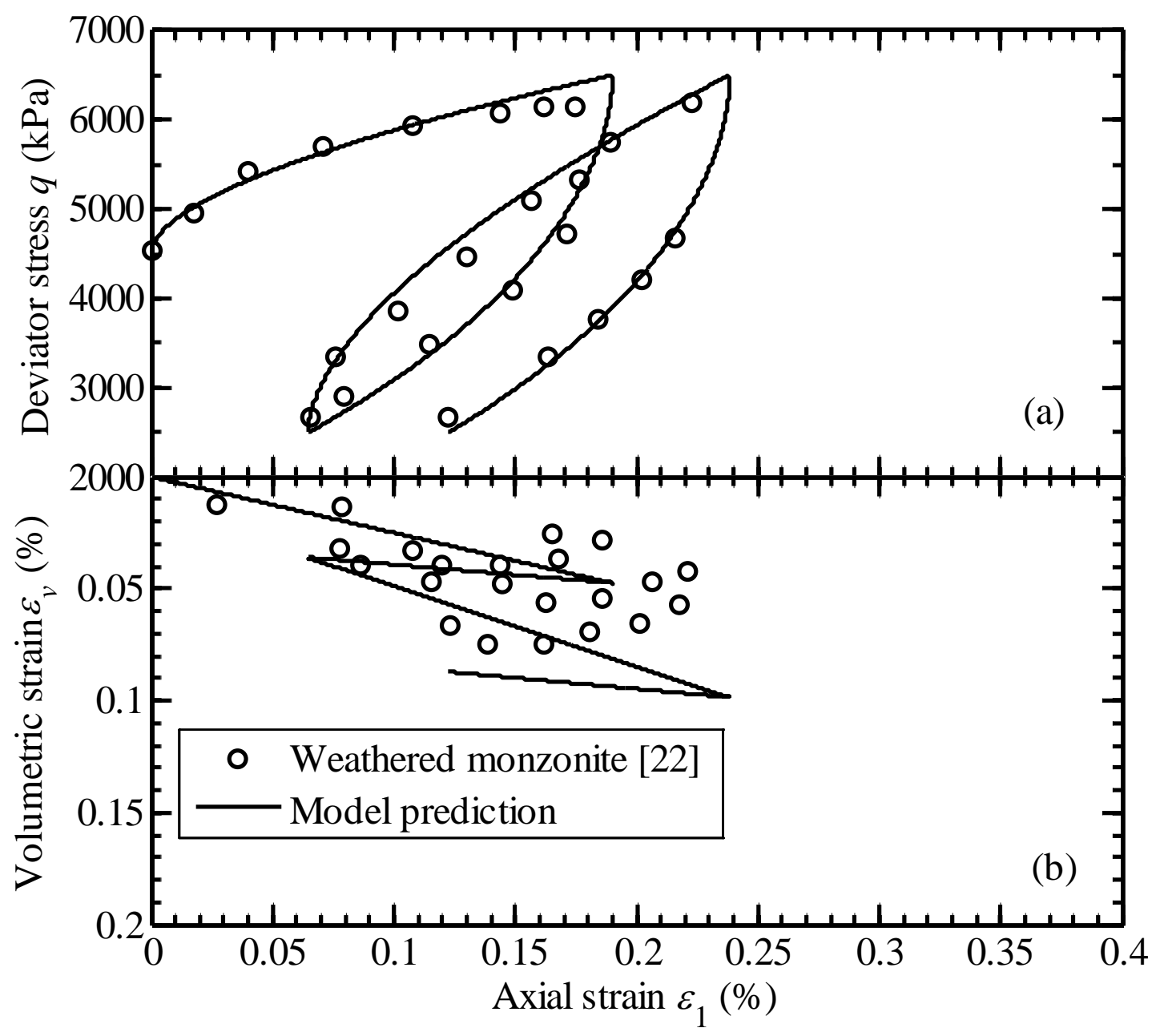

Fig. 10. Representation of the stress strain behaviour of weathered monzonite [22] 